\title{
An unusual case of both bones forearm shaft fracture with ipsilateral distal radio-ulnar joint disruption
}

\author{
Atul Rai Sharma ${ }^{\circledR}$, Akash Singhal ${ }^{\circledR}{ }^{\circledR}$, Anurag Patil ${ }^{\circledR}$, Gladson David Masih ${ }^{\circledR}$ \\ Department of Orthopaedics, Government Medical College Hospital, Sector 32, Chandigarh, 160030, India
}

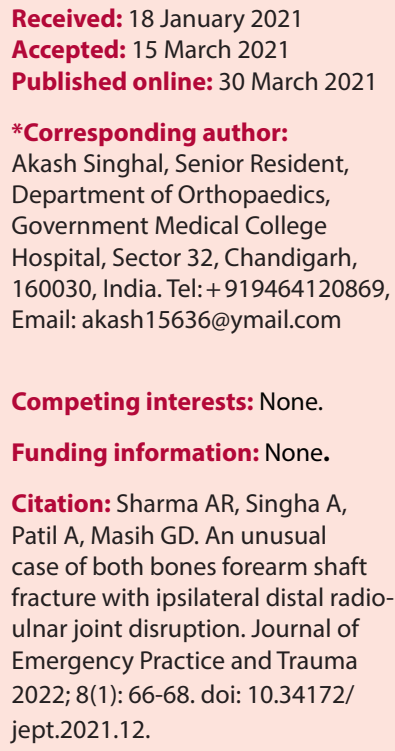

\begin{abstract}
Objective: Distal radioulnar joint (DRUJ) subluxation with associated both bones forearm fracture is a rare clinical entity and is easily missed, leading to significant functional limitations.

Case Presentation: A 28-year-old male fell on the outstretched hand and suffered left side both bones forearm shaft fracture with ipsilateral DRUJ disruption. Operative intervention in the form of plating was done for both bones forearm shaft fracture and DRUJ was stabilised with one $\mathrm{k}$ wire and above elbow plaster splint in full supination was given for 6 weeks. At one-year follow-up, fracture was united and Disabilities of the Arm, Shoulder and Hand (DASH) score was 11.7, and he was well satisfied.

Conclusion: DRUJ disruption should be carefully evaluated in all the patients with associated shaft fractures of radius and ulna. Timely diagnosis and optimal intervention may prevent any functional limitations.

Keywords: Distal Radioulnar Joint, Forearm Fracture, Ipsilateral, Case Report
\end{abstract}

\section{Introduction}

Forearm consists of two bones; radius and ulna, which along with interosseous membrane and radioulnar joints forms a complex functional entity, responsible for pronation and supination (1). Fracture dislocation of this complex anatomical entity may lead to the significant functional disability $(2,3)$. Whereas incidences of distal radioulnar joint (DRUJ) disruption with isolated radius shaft are commonly reported (Galeazzi fracture), DRUJ injury along with both bones forearm shaft fracture is a rare clinical entity (4). An incidence of 1.35 per 100000 adults for both bones forearm fractures is reported, with less than $7 \%$ of patients accounting for the associated radioulnar joint injury (5).

The DRUJ subluxations are usually dorsal and are commonly missed (4). Further, as reported by RodriguezMartin and Pretell-Mazzini, no single imaging can properly rule out the dislocations associated with forearm fractures pre-operatively and thus proper clinical examination both preoperatively and intra-operatively, along with the proper imaging, can help prevent missing of injuries (6). We report a rare case of both bones forearm shaft fracture with ipsilateral DRUJ disruption.

\section{Case Presentation}

A 28-year-old male suffered a high energy trauma when he was riding a bicycle and hit by a car from the back, following which he fell on the outstretched hand. The patient was taken to the local hospital where he was stabilised and referred to the trauma centre of our institute for further management. At our hospital after stabilising the patient, temporary cardboard splint was given on left forearm and x-rays were done. Following radiographic analysis, the patient sustained a closed left sided both bones forearm shaft fracture with ipsilateral (left) DRUJ disruption (Figure 1). There were no other associated injuries of the head, blunt trauma chest or blunt trauma abdomen. Plan for both bones forearm fracture fixation with plating and DRUJ reduction, with/without stabilisation with $\mathrm{k}$ wires was made. Radius fracture was explored through Volar approach and ulna with the standard subcutaneous technique between the flexor and extensor muscle compartments $(7,8)$ and fixation was done with 7-hole compression plating technique with 3 bicortical screws on either side of the fracture (Figure 2). On the assessment of DRUJ stability with DRUJ ballottement test intra-operatively following fixation of 
both bones forearm fracture, it was found to be unstable, following which temporary stabilisation of DRUJ with $1 \mathrm{k}$ wire in the supinated forearm was done (Figure 2). Post-operatively distal neurovascular status was normal and above elbow, plaster slab was given in full supination for 6 weeks. Single shot of injection cefuroxime was given postoperatively and sterile dressing was done after 48 hours. Suture removal was done after 2 weeks in the outpatient department. Plaster splint was removed after 6 weeks and gentle elbow, wrist and hand mobilisation exercises were started. In due course of time, movements were increased gradually and the patient was followed up till union. At 1 year follow-up, the fracture had completely united (Figure 3) with Disabilities of the Arm, Shoulder and Hand (DASH) score of 11.7 and elbow range of movements from 0 to 135 degrees and forearm pronation and supination from 0-75 degrees and 0-80 degrees, respectively and the patient was well contented (9).

\section{Discussion}

The association of diaphyseal forearm bone fractures

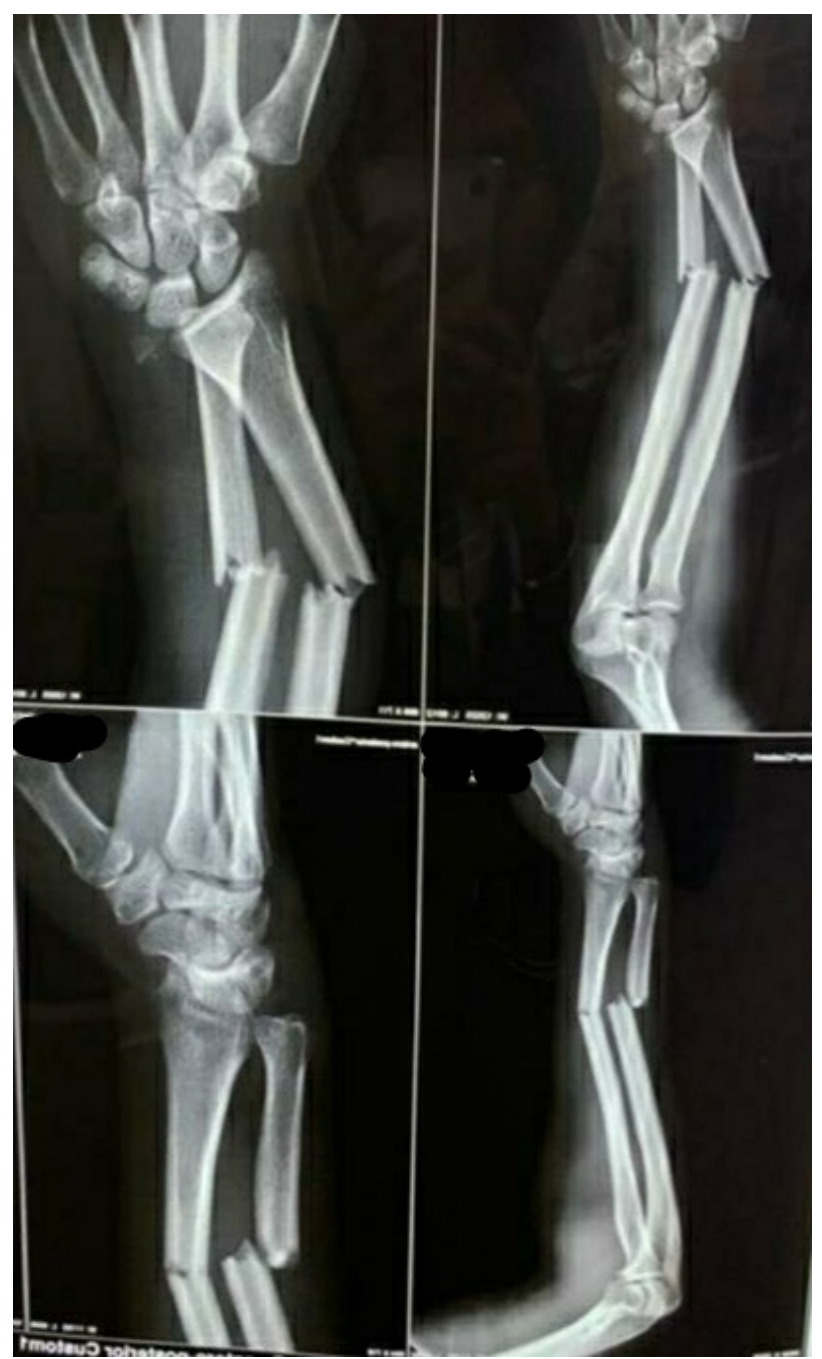

Figure 1. Radiographic anteroposterior and lateral views showing fracture of radius and ulna shaft with DRUJ disruption.

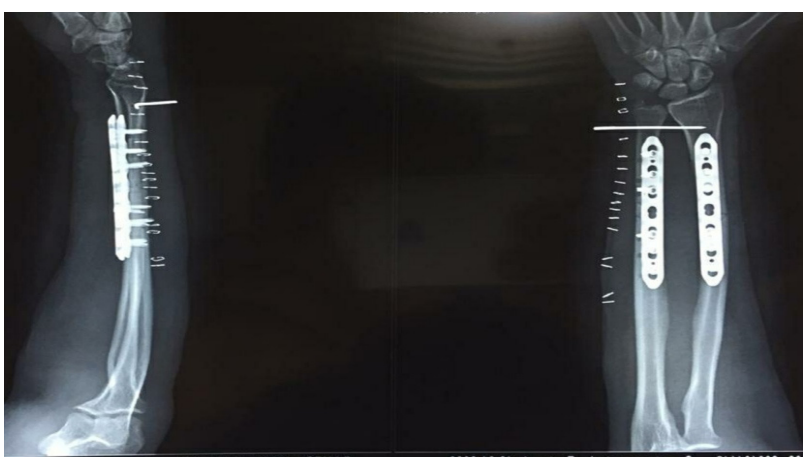

Figure 2. Immediate postoperative radiographic anteroposterior and lateral views showing fixation of radius and ulna shaft fractures with plating and $1 \mathrm{k}$ wire for DRUJ disruption.

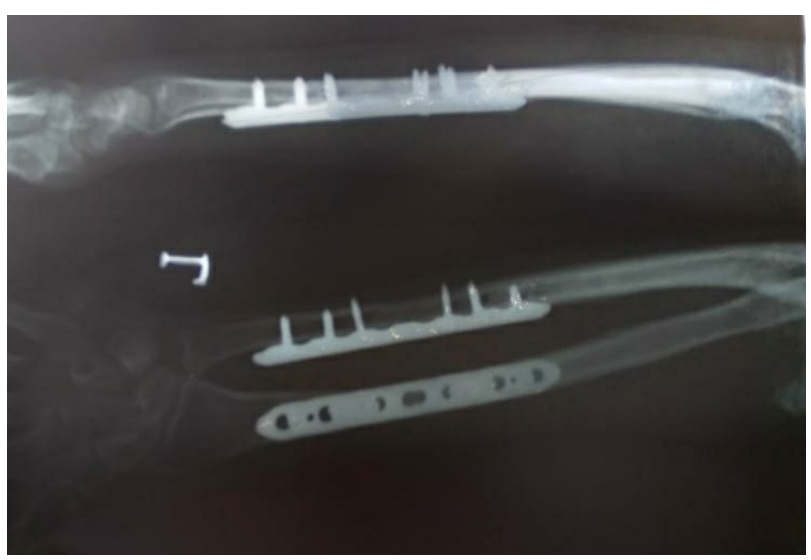

Figure 3. One year follow-up radiographic anteroposterior and lateral views show complete union of the fracture

along with DRUJ injury is a rare instance and occurs as a result of continued axial force when fell on an outstretched hand $(10,11)$. Careful assessment of underlying soft-tissue and neurovascular injury, apart from the exclusion of impending compartment syndrome, is warranted in this regard (1). The gold standard treatment for the adult both bones forearm shaft fractures remains to be compression plating for $2 \mathrm{R} / 2 \mathrm{U} 2 \mathrm{~A} / \mathrm{B}$ type fractures and bridge plating for $2 \mathrm{R} / 2 \mathrm{U} 2 \mathrm{C}$ type fractures (AO/OTA classification) (1). The anatomical reduction needs to be achieved along with radioulnar joint reduction, to prevent any rotatory disabilities as reported by Matthews et al and Dumont et al in their respective studies $(2,3)$.

DRUJ disruption may occur as an isolated injury or in rare cases may present with fractures radius and ulna (12). The direction of the dislocation is usually dorsal and is determined by the position of the ulna in comparison to the radius on radiographic x-rays (12). Despite adequate imaging and clinical examinations, DRUJ injuries may remain undiagnosed and may lead to the ulnocarpal abutment, radial and ulnar sided pain and forearm functional impairments (4). Further, inadequate reduction leads to the future degenerative diseases and chronic irreducible dislocations (4). While in most of the acute trauma cases, after satisfactory fixation of the 
radius and/or ulna fracture, DRUJ gets reduced, in few instances DRUJ needs to be reduced by open technique with/without triangular fibrocartilage complex (TFCC) repair and temporary stabilisation with plaster or $\mathrm{k}$ wires $(5,12)$. Moreover, in most of these acute trauma cases if fracture dislocation is timely intervened, the resultant would be satisfactory long term outcomes (4). However, in cases of missed DRUJ injury or late presentation, first and foremost is to try for closed reduction and if that fails, emergent open reduction of the DRUJ should be done. Further in some cases, where open reduction fails to achieve acceptable reduction, salvage procedures in the form of Darrach's procedure or late repair of TFCC or Sauve Kapandji procedure needs to be done $(5,12)$.

The current case report describes a rare injury pattern and highlights the importance of sticking to standard protocols of fracture fixation and early diagnosis of DRUJ disruption to manage these complex injuries.

\section{Clinical Message}

DRUJ injury may be easily missed when associated with both bones forearm fracture due to its rare occurrence. Further, DRUJ ballottement test should be done after fixation of forearm fractures, as delayed diagnosis leads to significant morbidity with patients less likely to achieve satisfactory functional rotatory range of movement, joint congruency and stability.

\section{Conclusion}

Early diagnosis and optimal reduction of DRUJ associated with forearm shaft fractures help in achieving excellent results.

\section{Authors' contribution}

AR performed the surgery and conceptualized the study. AS assisted in the operative procedure. AP wrote the manuscript. GM did the editing of the manuscript. All authors approved final manuscript.

\section{Ethical issues}

Written informed consent was taken from the patient for publication of this case report and accompanying images. A copy of the written consent is available for review by the Editor-in-Chief of the journal on request.

\section{References}

1. Kim SB, Heo YM, Yi JW, Lee JB, Lim BG. Shaft fractures of both forearm bones: the outcomes of surgical treatment with plating only and combined plating and intramedullary nailing. Clin Orthop Surg 2015; 7(3): 282-90. doi: 10.4055/ cios.2015.7.3.282.

2. Dumont CE, Thalmann R, Macy JC. The effect of rotational malunion of the radius and the ulna on supination and pronation. J Bone Joint Surg Br 2002; 84(7): 1070-4. doi: 10.1302/0301-620x.84b7.12593.

3. Matthews LS, Kaufer H, Garver DF, Sonstegard DA. The effect on supination-pronation of angular malalignment of fractures of both bones of the forearm. J Bone Joint Surg Am 1982; 64(1): 14-7.

4. Mirghasemi AR, Lee DJ, Rahimi N, Rashidinia S, Elfar JC. Distal radioulnar joint instability. Geriatr Orthop Surg Rehabil 2015; 6(3): 225-9. doi: 10.1177/2151458515584050.

5. Streubel PN, Pesántez RF. Diaphyseal fractures of the radius and ulna. In: Rockwood, Green, and Wilkins Fractures in Adults and Children. 8th ed. Wolters Kluwer Health Adis (ESP); 2014.

6. Rodriguez-Martin J, Pretell-Mazzini J. The role of ultrasound and magnetic resonance imaging in the evaluation of the forearm interosseous membrane. A review. Skeletal Radiol 2011; 40(12): 1515-22. doi: 10.1007/ s00256-011-1190-7.

7. Henry AK. Complete Exposure of the Radius. Bristol, England: John Wright \& Sons Ltd; 1927.

8. Catalano LW 3rd, Zlotolow DA, Hitchcock PB, Shah $\mathrm{SN}$, Barron OA. Surgical exposures of the radius and ulna. J Am Acad Orthop Surg 2011; 19(7): 430-8. doi: 10.5435/00124635-201107000-00006.

9. Gummesson C, Atroshi I, Ekdahl C. The disabilities of the arm, shoulder and hand (DASH) outcome questionnaire: longitudinal construct validity and measuring self-rated health change after surgery. BMC Musculoskelet Disord 2003; 4: 11. doi: 10.1186/1471-2474-4-11.

10. Kose O, Durakbasa MO, Islam NC. Posterolateral elbow dislocation with ipsilateral radial and ulnar diaphyseal fractures: a case report. J Orthop Surg (Hong Kong) 2008; 16(1): 122-3. doi: 10.1177/230949900801600129.

11. Fleming FJ, Flavin R, Poynton AR, Glynn T. Elbow dislocation with ipsilateral open radial and ulnar diaphyseal fractures--a rare combination. Injury 2004; 35(1): 90-2. doi: 10.1016/s0020-1383(02)00143-2.

12. Wijffels M, Brink P, Schipper I. Clinical and non-clinical aspects of distal radioulnar joint instability. Open Orthop J 2012; 6: 204-10. doi: 10.2174/1874325001206010204.

13. Dukan R, Kassab Hassan S, Delvaque JG, Khaled I, Nizard R. Isolated volar dislocation of the distal radioulnar joint: a case report. J Orthop Case Rep 2020; 10(2): 97-100. doi: 10.13107/jocr.2020.v10.i02.1716. 